\title{
The Revised Korean Practice Parameter for the Treatment of Attention-Deficit Hyperactivity Disorder (III)
}

\author{
- Pharmacological Treatment -
}

\author{
Hyo-Won Kim 1 , Eunjoo Kim², Ji-Hoon $\mathrm{Kim}^{3}$, Jangho Park ${ }^{4}$, Geon Ho Bahn ${ }^{5}$, \\ Yeon Jung Lee ${ }^{6}$, Kyungun Jhung $^{7}$, and Dongwon Shin ${ }^{8}$ \\ ${ }^{1}$ Department of Psychiatry, University of Ulsan College of Medicine, Asan Medical Center, Seoul, Korea \\ ${ }^{2}$ Department of Psychiatry, Yonsei University College of Medicine, Gangnam Severance Hospital, Seoul, Korea \\ ${ }^{3}$ Department of Psychiatry, Pusan National University School of Medicine, Busan, Korea \\ ${ }^{4}$ Department of Psychiatry, University of Ulsan College of Medicine, Ulsan University Hospital, Ulsan, Korea \\ ${ }^{5}$ Department of Psychiatry, Kyung Hee University School of Medicine, Seoul, Korea \\ ${ }^{6}$ Department of Psychiatry, Soonchunhyang University Seoul Hospital, Seoul, Korea \\ ${ }^{7}$ Department of Psychiatry, International St. Mary's Hospital, Catholic Kwandong University, Incheon, Korea \\ ${ }^{8}$ Department of Psychiatry, Sungkyunkwan University School of Medicine, Kangbuk Samsung Hospital, Seoul, Korea
}

\section{주의력결핍 과잉행동장애 한국형 치료 권고안 개정안(II) \\ - 약물치료 -}

\author{
김효원 ${ }^{1}$, 김은주 ${ }^{2}$, 김지훈 ${ }^{3}$, 박장호 $^{4}$, 반건호 $^{5}$, 이연정 $^{6}$, 정경운 $^{7}$, 신동원 $^{8}$ \\ 울산대학교 의과대학 서울아산병원 정신건강의학교실, ${ }^{1}$ 연세대학교 의과대학 강남세브란스병원 정신건강의학교실, ${ }^{2}$ \\ 부산대학교 의학전문대학원 정신건강의학교실, ${ }^{3}$ 울산대학교 의과대학 울산대학교병원 정신건강의학교실, ${ }^{4}$ \\ 경희대학교 의학전문대학원 정신건강의학교실, ${ }^{5}$ 순천향대학교 서울병원 정신건강의학과, ${ }^{6}$ \\ 가톨릭관동대학교 국제성모병원 정신건강의학교실, ${ }^{7}$ 성균관대학교 의과대학 강북삼성병원 정신건강의학교실 ${ }^{8}$
}

\begin{abstract}
The objective of this review is the revision of the Korean practice parameters for the pharmacological treatment of attention-deficit hyperactivity disorder (ADHD) based on the change in the diagnostic system from DSM-IV-TR to DSM-5 and psychopharmacological developments. For the evidence-based approach, the authors conducted a review of the literature, including controlled clinical trials, studies of the side effects of drugs, toxicology and meta-analyses from the United States and Europe, as well as recent research conducted in Korea. The review committee composed of Korean experts on ADHD reviewed the revised parameters. This revised version reveals how to use central nervous system psychostimulants, non-stimulants such as atomoxetine and alpha2 agonists, and other medication for ADHD, and how to manage the adverse effects of such medication. At the end of this revised version, the authors propose recommendations for the pharmacotherapy of ADHD.
\end{abstract}

Key Words: Attention-deficit hyperactivity disorder; Psychostimulant; Non-stimulant; Pharmacotherapy.

Received: March 4, 2017 / Revision: March 10, 2017 / Accepted: March 10, 2017

Address for correspondence: Dongwon Shin, Department of Psychiatry, Sungkyunkwan University School of Medicine, Kangbuk Samsung Hospital, 29 Saemunan-ro, Jongno-gu, Seoul 03181, Korea

Tel: +82-2-2001-2213, Fax: +82-2-2001-2211, E-mail: ntour@unitel.co.kr

서 론

주의력결핍 과잉행동장애(attention-deficit hyperactivity disorder, $\mathrm{ADHD})$ 의 치료에서는 약물치료와 비약물치료가 상

This is an Open Access article distributed under the terms of the Creative Commons Attribution Non-Commercial License (http://creativecommons.org/licenses/by-nc/4.0) which permits unrestricted non-commercial use, distribution, and reproduction in any medium, provided the original work is properly cited.
호보완적인 역할을 한다. 치료 초기 또는 기능상 문제가 심하 지 않은 경우 비약물치료를 우선 시행할 수 있으나, 기능상 문 제가 상당한 경우라면 치료 초기부터 약물치료가 필요하다. $\mathrm{ADHD}$ 의 병태생리와 중추신경자극제의 약리학적 기전에 대 한 연구들이 활발히 이루어지고, Multimodal Treatment of Attention-Deficit Hyperactivity Disorder Study(MTA) 연구 에서 약물치료가 행동치료보다 ADHD 증상 호전에서 우월한 
효과를 보이는 것이 알려지면서, ${ }^{1)}$ 현재는 약물치료가 $\mathrm{ADHD}$ 의 일차적인 치료로 생각되고 있다.

현재 ADHD 치료제로 한국 식품의약품안전처의 승인을 받 은 약물로는 중추신경자극제인 메칠페니데이트(methylphenidate), 비중추신경자극제 중에는 아토목세틴(atomoxetine) 과 $\alpha 2$-agonist 계열 약물인 클로니딘(clonidine)이 있다. 그 외 삼환계 항우울제(tricyclic antidepressants)와 부프로피온 (bupropion)이 ADHD 증상을 호전시키는 것으로 알려져 있지 만 식품의약품안전처의 승인을 받지 못해 off-label로만 사용 이 가능하다.

\section{국내에서 사용 가능한 $A D H D$ 약물}

\section{중추신경자극제(Psychostimulants)}

중추신경자극제는 전전두피질의 도파민과 노르아드레날 린, 선조체의 도파민 세포외 농도(extracellular concentration) 를 증가시키는 약물로 부주의, 과잉행동, 충동성 같은 $\mathrm{ADHD}$ 핵심 증상을 호전시킬 뿐 아니라 문제행동을 줄여주며 학업능 력을 증진하고 적절한 교우관계를 유지하는 데에 도움이 된 다. ADHD 아동을 대상으로 한 대규모 약물연구인 MTA 연구 에서는 중추신경자극제의 사용으로 $\mathrm{ADHD}$ 의 증상이 효과적 으로 호전되었으며, 약 $70 \%$ 에서 치료 반응을 보였다. ${ }^{2.3)}$ 국내 $\mathrm{ADHD}$ 아동청소년을 대상으로 한 연구에서도 $\mathrm{ADHD}$ 증상의 상당한 호전을 보였으며, ${ }^{4}$ 신경인지검사에서 유의한 호전을 보 였을 뿐 아니라, ${ }^{5)}$ 부모 및 또래관계 등의 기능 ${ }^{6,7}$ 과 삶의 질 ${ }^{8}$ 을 개선시키는 것으로 보고되었다.

약제는 크게 속효성과 지속형 제제로 출시되어 있으며, 환아 의 연령, 체중, 증상의 정도 등에 따라 적절한 제형을 선택하여 사용한다. 국내에서 사용 가능한 중추신경자극제의 제형 및 용량은 Table 1에 요약되어 있다.
속효성 메칠페니데이트(Immediate-release methylphenidate)

속효성 메칠페니데이트는 복용 후 1 3시간 후에 혈장 최고 농도에 도달하며, 효과가 약 4시간 정도 지속되기 때문에 하 루 2 3회 복용해야 하는 번거로움이 있다. 학교에서 약물 복 용을 챙겨주지 않으면 약효가 떨어지는 시점에 아동의 주의력 이 약해져 약 복용을 잊기도 하고, 때로는 친구들의 시선을 의식하여 아동 스스로 약 먹기를 꺼리기도 한다. 따라서, 오 전 약물 복용률에 비해 오후 시간대의 약물순응도는 크게 낮 아진다.9) 또한 약 효과가 떨어질 때쯤 반동 현상으로 산만한 증상이 더 심해지는 단점도 있다.

\section{지속형 메칠페니데이트(Long-acting methylphenidate)}

속효성 메칠페니데이트의 이러한 단점을 보완하기 위해서 다양한 제형의 지속형 메칠페니데이트가 개발되었다. 약물의 효과가 8 12시간 정도로 오래 유지되어 학교에서는 약물을 복용하지 않아도 되어 약물순응도가 좋아졌다. 현재 우리나 라에서 사용 가능한 지속형 메칠페니데이트에는 다음과 같은 약물들이 있다.

오로스 메칠페니데이트(Methylphenidate osmotic controlledrelease oral delivery system)

콘서타 $\left(\right.$ Concerta $\left.{ }^{\circledR}\right)$ 는 삼투압 원리를 이용하여 약물의 흡수 속도를 조절하는 osmotic controlled-release oral delivery system(ORSO) 기술을 사용하여 개발된 약물로, 복용 후 1 2시 간 만에 최고 농도에 올라가고 이후 메칠페니데이트 성분을 서서히 방출함으로써 한 번의 복용으로 약효가 대략 12시간 지속된다. ${ }^{10,11}$ 콘서타는 서방형으로 개발된 다른 메칠페니데이 트 계열의 제품보다 긴 작용시간을 가지고 있다는 장점이 있어 임상에서 가장 널리 쓰이고 있는 약물이다.

Table 1. Drugs with KMFDS approval for ADHD

\begin{tabular}{|c|c|c|c|}
\hline Generic name & Brand name & Usual daily dose, mg (mg/kg)* & Duration of effect (hour) \\
\hline \multicolumn{4}{|l|}{ Methylphenidate } \\
\hline Methylphenidate IR & Penid $(\mathrm{T})$, perospin $(\mathrm{T})$ & $10-60(0.3-1.5)$ & $3-5$ \\
\hline Methylphenidate ER & $\begin{array}{l}\text { Metadate CD ER }(C) \\
\text { medikinet retard }(C)\end{array}$ & $20-60(0.6-1.5)$ & $6-8$ \\
\hline Methylphenidate OROS & Concerta OROS ER (T) & $18-72(0.4-1.8)$ & 12 \\
\hline \multicolumn{4}{|c|}{ Norepinephrine-reuptake inhibitor } \\
\hline Atomoxetine & $\begin{array}{l}\text { Strattera }(C) \text {, atomoxin }(C) \\
\text { atocera }(C), \text { atomoxetine }(C)\end{array}$ & $18-100(0.7-1.4)$ & At least 10-12 \\
\hline \multicolumn{4}{|l|}{ a2-Adrenergic agonists } \\
\hline Clonidine ER & Kapvay ER (T) & $0.1-0.4$ & At least 10-12 \\
\hline
\end{tabular}

*usual dose should not be interpreted as a cap or a minimal effective dose if a higher or lower dose is clinically indicated in individual cases. ADHD: attention-deficit hyperactivity disorder, C: capsule, ER: extended release, IR: immediate release, KMFDS: Korean Ministry of Food and Drug Safety, OROS: osmotic controlled-release oral delivery system, T: tablet 
서방형 메칠페니데이트(Methylphenidate extended release) 현재 한국에서 처방 가능한 서방형 메칠페니데이트에는 메 타데이트(metadata $\mathrm{CD}$ )와 메디키넷 리타드(medikinet retard)
가 있다. 메타데이트는 미국에서 처음 $\mathrm{ADHD}$ 치료제로 승인 을 받은 약물로 속효성 대 서방형 메칠페니데이트가 3:7 비율 로 섞여 있다. ${ }^{12)}$ 이 약물 역시 통째로 삼키는 복용법을 권장하

Table 2. Monitoring and management of methylphenidate side effect

\begin{tabular}{|c|c|c|}
\hline Side effect & Monitoring & Management \\
\hline $\begin{array}{l}\text { Appetite loss or } \\
\text { weight loss }\end{array}$ & $\begin{array}{l}\text { Check body weight: before and every } \\
3-6 \text { months after the treatment } \\
\text { Compare weight with normal growth curve }\end{array}$ & $\begin{array}{l}\text { Recommend psychostimulant intake after meals } \\
\text { Education regarding diet }\end{array}$ \\
\hline $\begin{array}{l}\text { Height growth } \\
\text { delay }\end{array}$ & $\begin{array}{l}\text { Check height: before and every } 3-6 \text { months } \\
\text { after the treatment } \\
\text { Compare height with normal growth curve }\end{array}$ & $\begin{array}{l}\text { Consider taking drug holidays } \\
\text { Consider dosage reduction or interruption } \\
\text { of medication when clear evidence of growth delay is present }\end{array}$ \\
\hline Sleep problems & $\begin{array}{l}\text { Compare sleep patterns before and after } \\
\text { the treatment }\end{array}$ & $\begin{array}{l}\text { Consider dosage reduction or change of medication } \\
\text { taking time } \\
\text { Consider changing to atomoxetine treatment }\end{array}$ \\
\hline $\begin{array}{l}\text { Cardiovascular } \\
\text { problems }\end{array}$ & $\begin{array}{l}\text { Check history of heart problems or } \\
\text { cardiovascular symptoms (fainting, dizziness, } \\
\text { or irregular heart rate) before the treatment } \\
\text { with psychostimulants } \\
\text { Check family history of major heart problems } \\
\text { or sudden death in young relatives before } \\
\text { the treatment } \\
\text { Check heart rate, blood pressure, and heart } \\
\text { murmur periodically in adult patients }\end{array}$ & $\begin{array}{l}\text { Not routinely recommended ECG screening } \\
\text { in healthy children } \\
\text { Consult a cardiologist before the treatment if there } \\
\text { is suspicion of high cardiovascular risk } \\
\text { Stop medication and consult a cardiologist if the } \\
\text { blood pressure is higher than } 95 \text { percentile (or if a clinically } \\
\text { significant increase is observed), or in case of arrhythmia/ } \\
\text { tachycardia after the treatment with psychostimulants has } \\
\text { started } \\
\text { Children with known cardiac conditions should be monitored } \\
\text { by their own physicians }\end{array}$ \\
\hline Seizure & $\begin{array}{l}\text { Check past history and symptoms of seizures; } \\
\text { and assess developmental delay } \\
\text { Explain seizures risk to guardians }\end{array}$ & $\begin{array}{l}\text { Seizures disorders should be stabilized with anticonvulsants } \\
\text { before the start of the treatment with psychostimulants } \\
\text { Slow dosage titration } \\
\text { Consider dosage reduction or interruption of psychostimulant } \\
\text { Consider changing to atomoxetine treatment }\end{array}$ \\
\hline Tic symptom & $\begin{array}{l}\text { Compare tic symptoms before and after the } \\
\text { treatment } \\
\text { Inform guardians that ADHD medications do } \\
\text { not cause tics; however, some medications } \\
\text { may increase or reduce tics }\end{array}$ & $\begin{array}{l}\text { Consider dosage reduction or interruption of psychostimulant } \\
\text { if tic symptoms are caused, or aggravated, } \\
\text { by psychostimulants treatment } \\
\text { Consider changing to atomoxetine treatment }\end{array}$ \\
\hline $\begin{array}{l}\text { Behavioral } \\
\text { rebound }\end{array}$ & $\begin{array}{l}\text { Compare irritability and ADHD symptoms } \\
\text { before and after the treatment }\end{array}$ & $\begin{array}{l}\text { Slow dosage titration } \\
\text { Take a long-acting psychostimulant in the morning to curb } \\
\text { this late-day effect } \\
\text { Consider changing to atomoxetine treatment }\end{array}$ \\
\hline $\begin{array}{l}\text { Psychotic } \\
\text { symptoms }\end{array}$ & $\begin{array}{l}\text { Compare psychotic symptoms before and } \\
\text { after the treatment }\end{array}$ & $\begin{array}{l}\text { Stop psychostimulants if psychotic symptoms are caused by } \\
\text { psychostimulants treatment } \\
\text { Treat psychotic symptoms using antipsychotics if psychotic } \\
\text { symptoms continue after stopping the psychostimulants } \\
\text { treatment } \\
\text { Consider changing to atomoxetine treatment }\end{array}$ \\
\hline Abuse or misuse & $\begin{array}{l}\text { Check abuse potential before starting the } \\
\text { treatment } \\
\text { Check family history of alcohol or drug abuse } \\
\text { before starting the treatment }\end{array}$ & $\begin{array}{l}\text { Educate parents or guardians about the necessity to [1] store } \\
\text { the psychostimulants in a secure place, and [2] monitor } \\
\text { psychostimulants usage } \\
\text { Consider changing to atomoxetine treatment if there is suspicion } \\
\text { of high abuse potency }\end{array}$ \\
\hline
\end{tabular}

ADHD: attention-deficit hyperactivity disorder, ECG: electrocardiography 
고 있으나 캡슐 안의 내용물을 주스 같은 음식물에 뿌려서 복용하는 방법도 가능하다. 투약 1.5 시간 뒤와 4.5 시간 후에 두 번 최고 혈중농도를 보이며 효과는 8 12시간까지도 지속 된다. ${ }^{13)}$

메디키넷은 속효성 대 서방형 메칠페니데이트 비율이 5:5이 다. 최고 농도에 빠르게 도달하여 약효가 빠르게 발현되며, 3 4시간 뒤 두 번째 최고 농도에 도달한다. ${ }^{12}$ 이 약물 또한 캡슐 그대로 삼키는 것이 좋으나, 유동식에 뿌려서 복용해도 된다.

\section{아토목세틴(Atomoxetine)}

아토목세틴은 미국 Food and Drug Administration(FDA) 에서 비중추신경자극제로는 최초로 $\mathrm{ADHD}$ 치료제로 승인한 약제로, $\mathrm{ADHD}$ 아동, 청소년, 성인의 치료에 있어 위약보다 좋 은 효과를 보였다. ${ }^{14-17)}$ 아토목세틴과 메칠페니데이트의 무작 위 개방 비교 연구에서 두 약물의 치료 효과는 같고, 아토목세 틴이 약물남용 및 심혈관 부작용에 대해 더욱 안전하다고 보 고되었다. ${ }^{18}$ 한편, 대규모 이중맹검 위약 비교 연구에서는 메칠 페니데이트의 효과크기(effect size)가 1.0일 때 아토목세틴의 효과크기는 0.7 정도로 약간 낮은 편이었다. ${ }^{19)}$

아토목세틴은 중추신경자극제보다 효과가 천천히 나타나 고 임상적 변화도 점진적인 편으로, 최대 치료 효과는 6 8주 가 지나야 도달될 수도 있다. 용량은 $0.5 \mathrm{mg} / \mathrm{kg} / \mathrm{day}$ 로 시작하 여 7일 간격으로 치료 용량인 $1.2 \mathrm{mg} / \mathrm{kg} / \mathrm{day}$ 까지 서서히 증량 하며, $1.4 \mathrm{mg} / \mathrm{kg} / \mathrm{day}$ 까지 사용할 수 있다. 적대적 반항장애에 서는 $1.8 \mathrm{mg} / \mathrm{kg} / \mathrm{day}$ 에서도 다소의 호전이 관찰되기도 하였 으며 미국 소아청소년정신의학회에서는 최대 $2.2 \mathrm{mg} / \mathrm{kg} / \mathrm{day}$ 까지 사용할 수 있다고 보고하였다. ${ }^{20}$

아토목세틴은 약물남용의 위험성이 적고, 1 회 투여로 늦은 저녁과 이른 아침까지 포함하여 긴 시간 동안 약물 효과가 유 지되는 장점이 있다. 중추신경자극제 부작용으로 불면이나 식 욕부진이 심한 경우, 또는 틱장애나 불안장애가 동반질병으로 있는 경우 사용될 수 있다. $\mathrm{ADHD}$ 와 불안장애가 동반된 환 자를 대상으로 아토목세틴 사용 시 $\mathrm{ADHD}$ 증상과 불안이 모 두 의미 있게 감소되었다는 보고가 있다. ${ }^{21)}$ 국내 연구에서도 아토목세틴의 용량에 따라 $\mathrm{ADHD}$ 증상이 유의하게 호전되었 으며, 용량이 증가함에 따라 부작용의 호소는 많아졌으나, 모 든 용량에서 안전성과 내약성이 뛰어났다. ${ }^{22)}$

\section{$\alpha 2$ 작용제}

$\mathrm{ADHD}$ 에 사용되는 $\alpha 2$ 작용제로는 클로니딘(clonidine)과 구안파신(guanfacine)이 있으며, 최근 서방형 클로니딘이 국내 에 도입되어 사용되고 있다. 클로니딘은 단독 혹은 중추신경 자극제와의 병합요법으로 $\mathrm{ADHD}$ 증상을 감소시키며, 증상
감소에 대한 효과크기는 중추신경자극제보다 적지만 아토목 세틴과 비슷한 것으로 보고되고 있다.223) 특히 중추신경자극 제와 아토목세틴 치료 중에 틱, 수면장애, 감정 기복 등의 부 작용을 보이는 경우 $\alpha 2$ 작용제가 도움이 될 수 있다. ${ }^{24)}$

\section{부프로피온(Bupropion)}

부프로피온은 우울증과 금연 치료 보조제로 $\mathrm{FDA}$ 승인을 받은 약물이나, $\mathrm{ADHD}$ 증상을 감소시키는 데도 유의한 효과 를 보이고 있다. ${ }^{25)}$ 부프로피온과 메칠페니데이트를 비교한 4 개의 무작위 연구에 대한 체계적 고찰에서 부프로피온은 메 칠페니데이트에 대등한 효과를 보였으나, ${ }^{26)}$ 부프로피온과 다 른 $\mathrm{ADHD}$ 약물치료를 비교한 메타분석에서는 다른 약제에 비하여 위약 대비 효과가 작은 편이었다. ${ }^{27)}$ 우울증에서와 마 찬가지로 약물치료의 효과는 6 8주에 걸쳐서 나타난다.

\section{기타 약물}

모다피닐(modafinil)은 식품의약품안전처에서 기면증 치료 제로 승인된 약제로 $\mathrm{ADHD}$ 아동청소년에서 $\mathrm{ADHD}$ 증상을 유의미하게 감소시키는 것으로 보고되고 있으나 아직까지 식 품의약품안전처에서 $\mathrm{ADHD}$ 에 대한 사용이 허가되지는 않았 다. ${ }^{28-30)}$ 그 외 식품의약품안전처에서 허가를 받지는 못하였으 나 약물남용의 가능성이 있는 경우, 틱장애의 가족력이 있는 경우, 다른 약제가 효과가 없거나 부작용이 있어 사용하기 어 려운 경우 삼환계 항우울제도 고려해 볼 수 있다.23)

\section{약물 부작용 및 고려 사항}

약물치료를 시작하기 전에 환아 및 부모에게 중추신경자극 제의 효과와 함께 부작용에 대한 충분한 설명이 필요하다. 약 물 부작용은 치료순응도에 영향을 미쳐 예후에도 중요한 영 향을 주기 때문에, 보호자와 환아에게 미리 설명하고 교육하 여 부작용 발생 시 잘 대처할 수 있도록 하는 것이 중요하다.

\section{중추신경자극제}

흔히 보고되는 중추신경자극제의 부작용으로는 식욕부진, 복통, 두통, 불면, 자극과민성/감정 불안정성, 맥박과 혈압 증 가 등의 심혈관계 영향 등이 있다. ${ }^{3,31,32)}$ 대부분의 부작용은 주 로 치료 초기에 일시적으로 경미하게 나타나고 대체로 호전되 지만,3) 식욕부진, 체중 감소, 두통, 불면, 틱 등의 증상들이 해 소되지 않고 지속되는 경우에는, 약물을 감량하거나 다른 계열 의 약물로 교체하는 등으로 해결할 수 있다. ${ }^{3)}$ 한 가지 특정한 약물에 가장 효과적이나 부작용이 심각하게 동반되는 경우에 는 부작용을 줄일 수 있는 약물을 추가할 수 있다(Table 2). ${ }^{34)}$ 


\section{불면 및 식욕부진}

불면과 식욕부진은 중추신경자극제의 흔한 부작용이지만 약물 복용과 관계없이 증상의 악화나 재발에 의해서도 나타 날 수 있다. 따라서 약물치료 전 수면과 식사습관을 확인해 두 는 것이 도움이 된다. 약물에 의한 부작용인 경우 약물 복용 초기에 나타나기 때문에, 약물 투여 전후 식욕변화 양상을 주 의 깊게 관찰하는 것이 중요하다.

중추신경자극제 복용이 수면을 방해한다면 작용시간이 긴 중추신경자극제에서 작용시간이 짧은 약물로 교체하거나 약 물 복용시간을 좀 더 이른 시간으로 조정하여 숙면을 도울 수 있다. ${ }^{35)}$ 그래도 조절이 되지 않는 경우 소량의 클로니딘, 트라조 돈(trazodone), 멜라토닌(melatonin) 또는 항히스타민제 등이 도움이 될 수 있다. ${ }^{35,36)}$ 반대로 $\mathrm{ADHD}$ 아동의 행동문제 등 증 상의 악화로 인해 잠들기 어려운 경우에는 늦은 오후에 속효 성 약제를 투여하는 것이 수면에 도움이 된다. ${ }^{36)}$

$\mathrm{ADHD}$ 아동을 둔 부모들 중 일부는 중추신경자극제 복용 후 아동의 식욕이 줄어 하루 전체 식사량이 줄었거나 낮 동안 먹지 않다가 저녁 동안 너무 많은 양의 식사를 한다며 식사량 의 변화에 대해 걱정을 한다. 이처럼 식욕저하가 나타나는 경 우, 아침 식사 후 약물을 복용하게 해서 식욕저하를 줄이거나 고칼로리 음식과 음료를 주어 체중 저하를 줄일 수 있다. ${ }^{31)}$ 이 후에도 체중이 준다면 약물을 감량하거나 식욕저하가 덜 심 한 다른 계열의 중추신경자극제로 교체, ${ }^{35)}$ 혹은 사이프로헵타 딘(cyproheptadine)을 병용투약하는 것이 도움이 된다.37)

\section{자극과민성(Irritability)과 감정 불안정성}

중추신경자극제를 복용 중인 아동은 낮에 약물 농도가 유 지되는 동안 자극과민성/공격성이 나타날 수도 있고, 중추신 경자극제의 효과가 없어진 늦은 오후 시간에 과잉행동/충동 성이 증가할 수도 있다. 중추신경자극제가 활성화된 시간 동 안 나타나는 자극과민성/공격성의 경우 약물을 감량하거나 다른 유형의 중추신경자극제나 비중추신경자극제로 변경해 볼 수 있다. ${ }^{34)}$ 늦은 오후나 저녁시간에 과잉행동, 충동성과 부 주의함이 더 증가한다면 이는 중추신경자극제의 농도가 낮아 짐으로 인해 발생하는 반동이다. 이를 조절하기 위해서는 작 용시간이 긴 중추신경자극제를 투여 ${ }^{35}$ 하거나 늦은 오후에 적 정 용량의 속효성 중추신경자극제를 투여하는 것이 도움이 된다. ${ }^{34)}$

\section{심혈관계에 미치는 부작용}

드물게 나타나는 심장돌연사에 대한 논란을 포함하여 중 추신경자극제가 심장에 미치는 영향에 대해서는 논란이 있 다. ${ }^{38-40)}$ 그러나 최근 120 만 명 이상의 아동 및 젊은 성인 대상
의 후향적 코호트 연구에서는 $\mathrm{ADHD}$ 약물 사용과 급성 심정 지, 급성 심근경색, 뇌졸중과 같은 심각한 심혈관계 위험이 증 가한다는 증거는 없는 것으로 결론지었다.1) Shin 등 ${ }^{42)}$ 은 대한 민국의 국가 통계 자료를 이용한 연구를 통해 메칠페니데이트 를 투약한 아동청소년에서 치료 초기 부정맥이 늘어날 수 있 으나, 절대적인 비율은 상당히 적기 때문에 위험과 효과를 잘 판정하여 사용할 수 있음을 제시하였다. 그럼에도 불구하고, 임상에서는 중추신경자극제 처방 전에 심질환의 과거력이나 가족력이 없는지 확인하는 것이 도움이 될 수 있다. 현재까지 는 건강한 사람에서는 약물치료를 시작하기 전에 일상적으로 심장검사를 시행해야 한다는 근거는 없다.

\section{성장에 미치는 영향}

일반적으로 중추신경자극제 약물에 의해 최종 성인기 신장 은 영향을 받지 않는 것으로 알려져 있다. ${ }^{43}$ 일부 아이들의 경 우 약물치료 후 초기 2년간 키의 성장 속도가 지연되기도 하지 만 그 후 성장 속도는 정상 속도를 찾게 된다. ${ }^{35)} \mathrm{Kim}$ 등 는 은 년 이상 메칠페니데이트 투약을 지속한 157 명의 국내 아동을 대 상으로 한 연구에서, 처음 1 년 동안에는 신장과 체중이 예상치 에 비해 저하된 것으로 나타났으나, 1년 이후에는 성장이 일반 아동과 차이 없이 진행되는 것으로 보고하였다.

중추신경자극제를 복용 중인 아동은 최소 6 개월에 한 번 신장과 체중을 측정하는 것이 좋다. ${ }^{35)}$ 일반적으로 만 3 세 이 상 사춘기 이전 아동의 성장률은 1 년에 $4 \mathrm{~cm}$ 이상 되기 때문 에 ${ }^{45)}$ 성장 속도가 1 년에 $4 \mathrm{~cm}$ 이하로 지체된다면 약물 감량 및 교체 등을 고려하는 것이 바람직하다. ${ }^{34,35)}$

\section{약물휴일(Drug holiday)}

중추신경자극제를 복용 중이나 약물에 의한 부작용이 심 하거나 증상의 재평가 등을 목적으로 휴일이나 방학 동안 약 물을 중단하는 약물휴일에 대해 보호자들이 종종 문의해 온 다. 이러한 경우 $\mathrm{ADHD}$ 증상의 중증도, 부작용 등에 따라 약 물휴일을 가질 것인지 약물을 유지할 것인지 임상가가 판단 해야 한다. ${ }^{35)}$ 중추신경자극제를 복용 중인 아동에게 부작용 이 심한 경우 약물 용량을 줄이거나 약물휴일을 가질 수는 있 다. 그러나 약물 중단 시 $\mathrm{ADHD}$ 증상인 문제행동이 다시 나 타날 수 있으므로 중단 전에는 반드시 학교생활, 또래관계, 가족관계 등에서 아동의 증상을 명확히 확인해야 한다.

\section{의존 가능성}

상당수의 $\mathrm{ADHD}$ 아동의 부모들은 중추신경자극제 복용 시 그 약물에 중독이 되어 약을 끊지 못하게 될까 봐 걱정한 다. 하지만, 지금까지 연구결과들은 정반대의 결과를 보여준 
다. 아동이 중추신경자극제 치료를 지속한 경우 $\mathrm{ADHD}$ 증상 이 호전되어 청소년기가 되었을 때 흡연과 약물 중독 발생률 을 낮추고 발생 시기를 늦추며, ${ }^{46-48)}$ 성인이 되었을 때 약물과 관련된 범죄 발생률이 낮아진다고 보고한다. ${ }^{49)}$

\section{기타 부작용}

두통은 $\mathrm{ADHD}$ 로 인해 중추신경자극제를 투여받는 환자의 $3 \%$ 이상에서 나타나는 흔한 부작용이다. ${ }^{31)}$ 대부분 약물 복용 후 2 3시간 안에 두통이 유발되며 긴장성 두통(tension headache) 양상이다. 욱신거리는 양상의 혈관성 두통(vascular headache)도 발생할 수는 있으나 이는 약물 복용과 상관없이 이전 부터 편두통이 있었던 경우가 더 흔하다. 보통 두통은 약물 복용을 시작한 후 1 3주 이내 증상이 사라지지만 필요한 경우 아세트아미노펜과 같은 진통제가 도움이 된다. ${ }^{31)}$

중추신경자극제 사용과 관련하여, 드물지만 정신병적 증상 이나 조증이 나타날 수도 있다. ${ }^{50)}$ 중추신경자극제를 포함한 $\mathrm{ADHD}$ 치료제를 투약하면서 정신병적 증상이 일반 인구보 다 더 증가한다는 증거는 없지만, 조현병, 정신병적 증상이 동 반된 조증 환자나 기타 정신증을 갖고 있는 $\mathrm{ADHD}$ 아동에게 는 중추신경자극제 투약에 주의해야 한다. ${ }^{50)}$

\section{아토목세틴}

아토목세틴의 안전성을 살펴보기 위해 시행된 한 메타분석 연구에 따르면 식욕감소, 복통, 구토, 소화불량 등의 위장 관 련 증상 및 졸림 등의 수면 관련 증상이 가장 흔하게 나타났 다. ${ }^{51)}$ 나이가 어리거나 치료 시작 시 과잉행동/충동성 증상이 심 한 경우 부작용이 더 많았으며, 주의력결핍우세형에서 부작용 이 더 적었다. ${ }^{51)}$ 이러한 부작용은 대체로 용량을 조절하면 해 결되거나 시간이 지남에 따라 약화된다. 또한 졸림 및 위장관 계 증상 등의 초기 부작용을 줄이기 위해 점진적으로 증량하 고 아침과 저녁으로 나누어 주는 것이 도움이 될 수 있다. ${ }^{52,53)}$ 부작용이 지속된다면 점차 감량해서 중단하고 다른 약물을 시작해야 한다.

임상적 적응증이 있는 경우가 아니라면 정기적 혈액검사 및 심전도 검사는 권고되지 않으나, 혈압 및 맥박은 정기적으로 확인하는 것이 도움이 될 수 있다. 아동청소년 $\mathrm{ADHD}$ 환자에 서 아토목세틴 사용 시 혈압 및 맥박이 소폭 증가하였으며, 8 12\%에서는 $20 \mathrm{bpm}, 15 \sim 20 \mathrm{~mm} \mathrm{Hg}$ 이상의 변화가 보고되 었다. ${ }^{54)}$ 그러나 2년 이상 장기간 관찰 시에는 혈압은 정상 범위 안에 있었으며 심혈관계 부작용으로 약물 중단으로 이어진 환자는 소수였다.

아토목세틴과 관련된 간수치의 가역적 변화 사례 및 자살 사고 증가의 위험성이 보고된 바 있다. ${ }^{51,55)}$ 치료 중 간기능 추
적검사는 필수적이지 않으나, 황달 등의 간기능 장애의 임상 적 증상에 대해 알려주는 것이 좋다. 또한 치료 초기 및 용량 변화 시, 불안, 짜증, 자살사고, 자해행동, 평소와 다른 행동의 변화가 있는지 관찰해야 하며, 부모 및 보호자에게 이러한 변 화가 있을 시 보고하도록 한다.

성장과 관련하여 아토목세틴이 최종 성인 키에 미치는 영향 이 크지 않은 것으로 보고된 바 있으나, ${ }^{56,57)}$ 메칠페니데이트와 마찬가지로 정기적인 체중 및 신장 측정이 필요하다. 청소년 및 성인 $\mathrm{ADHD}$ 환자의 경우, 발기 및 사정 장애, 월경통 등의 부작용 발생 가능성을 고려해야 한다. ${ }^{58)}$ 아토목세틴과 같은 비중추신경자극제는 매일 일정 기간 이상 복용해야 충분한 효 과를 볼 수 있기 때문에 약물휴일을 갖는 것은 약물의 효과를 낮추고 금단증상을 유발할 수 있으므로 주의가 필요하다. ${ }^{35)}$

\section{$\alpha 2$ 작용제}

$\alpha 2$ 작용제의 가장 흔한 부작용은 졸림과 피곤이다. ${ }^{59)}$ 클로 니딘을 포함한 $\alpha 2$ 작용제는 혈압과 심박수를 다소 낮추는 효 과가 있으나 임상적 의미는 없는 것으로 보고되고 있다. ${ }^{60,611}$ 이 런 심혈관계 효과는 용량에 비례하기 때문에, ${ }^{61)}$ 적절한 용량까 지 천천히 증량하는 것이 중요하다. 과용량을 복용한 경우 저 혈압의 위험성이 있으며, 갑자기 중단할 경우 반동 고혈압(rebound hypertension)을 발생시킬 수 있다. ${ }^{35)}$

\section{기타 약물}

부프로피온의 부작용으로는 경도의 불면, 식욕감퇴, 과민 함, 졸림, 피로, 두통 및 틱 악화 등이 있을 수 있다. ${ }^{62}$ 모다피 닐은 두통, 불안, 과민함, 불면 등을 유발할 수 있다. ${ }^{23)}$

\section{특정 연령대에서의 약물치료}

\section{학령전기 아동의 약물치료}

학교를 들어가기 전 만 4 5세 아이들도 주의력결핍과 과잉 행동, 충동성 증상을 보이고 가정 및 교육기관에서 상당한 기 능의 저하를 보이는 경우 $\mathrm{ADHD}$ 로 진단되며, 부모 및 아동 을 대상으로 한 행동치료로 임상적 호전이 없는 경우 중추신 경자극제와 같은 약물치료가 도움이 될 수 있다. 그러나 식품 의약품안전처에서는 약물 사용 연령을 6세 이상으로 제한하 고 있으므로 학령전기 아동 대상 연구는 상대적으로 적은 편 이다.

미국 National Institutes of Mental Health에서 진행한 학령 전기 $\mathrm{ADHD}$ 치료 연구(Preschool ADHD Treatment Study)에 서 중추신경자극제는 학령전기 아동에서 $\mathrm{ADHD}$ 의 증상을 감소시키는 데 효과적인 것으로 보고되었으며, ${ }^{63)}$ 다른 연구에 
서도 $\mathrm{ADHD}$ 증상뿐 아니라 교사가 평가한 사회적 기능을 포 함한 기능상의 호전을 가져오는 것으로 보고되었다. ${ }^{64)}$ 그러나 학령기 아동에 비해 효과크기는 적은 것으로 보고되었으며, 만 4 5세 사이의 아동에 대한 중추신경자극제 효과에 대한 정보가 한정되어 있기 때문에 기능 저하의 정도가 중등도 이상 인 경우에만 약물치료를 고려해야 한다. ${ }^{63,65)}$

중추신경자극제를 투약한 학령전기 아동의 약 $30 \%$ 에서 부 작용이 나타나는 것으로 보고되었으며 학령기 아동에 비해서 감정 기복이나 과민함은 더 흔히 나타나지만, 식욕감소, 불면, 성장에 미치는 영향에는 차이가 없었다. ${ }^{63,65)}$ 만 4 5세의 아동 은 중추신경자극제 대사가 느리고 체중대비 용량이 같을 때 혈 중농도가 더 높다는 연구결과가 있으므로 초기 용량을 더 줄 이고 증량 역시 더 작은 단위로 시행하는 것이 안전하다. ${ }^{66}$

비중추신경자극제인 아토목세틴의 경우 12 명을 대상으로 한 소규모 자연적 추적 관찰연구에서 $75 \%$ 가 치료 반응을 보 인 바 있으나, ${ }^{67)}$ 아직 학령전기 아동에서의 효과와 안정성에 대한 연구가 더 필요한 상황이다. ${ }^{68)}$

\section{성인기 약물치료}

아동기에 $\mathrm{ADHD}$ 로 진단된 환자의 30 70\%가 청소년을 거 쳐 성인이 되어서도 $\mathrm{ADHD}$ 의 진단 기준을 만족하며, ${ }^{69)}$ 학업, 직장 생활 등에서 체계화, 충동조절, 결혼생활, 자녀 양육, 건 강관리 등 여러 영역에서 기능상의 저하를 가져오기 때문에,70) 약물치료가 필요한 경우가 많다. 국내에서도 성인 $\mathrm{ADHD}$ 의 치료에 대한 관심과 필요성이 증가하고 있으며, 2016년 9월 1 일부터 성인기에 처음으로 $\mathrm{ADHD}$ 로 진단받은 경우도 건강보 험이 적용되고 있다. 현재 국내에서 성인 $\mathrm{ADHD}$ 의 약물치료 에 승인받은 약물은 콘서타, 메디키넷, 아토목세틴이다.

최근에는 성인기에도 아동청소년의 경우와 마찬가지로 중 추신경자극제를 포함한 약물치료가 효과적이라는 연구결과 들이 보고되고 있다. ${ }^{2)}$ 성인 $\mathrm{ADHD}$ 에서 속효성 메칠페니데이 트를 $1.0 \mathrm{mg} / \mathrm{kg}$ 사용한 경우 반응률은 약 $78 \%$ 로 아동청소년 에서의 중추신경자극제에 대한 반응률과 유사하였다. ${ }^{71)} 1.3$ $\mathrm{mg} / \mathrm{kg}$ 이상의 콘서타를 사용한 대규모 연구에서 ADHD 환 자의 약 $2 / 3$ 에서 $30 \%$ 이상의 증상 감소를 보였으며, ${ }^{72)}$ 다른 연구에서는 보다 저용량의 콘서타에서도 효과를 보일 가능성 을 보고하였다. ${ }^{73)}$ 6개월 이상의 장기 연구에서도 메칠페니데 이트 사용 시 55 85\%에서 증상이 유의하게 감소하였다. ${ }^{74-76)}$ 이러한 연구결과들을 종합해 보면 메칠페니데이트는 성인 $\mathrm{ADHD}$ 환자들에게서 효과적인 치료제로 사용될 수 있다.

한편 성인 $\mathrm{ADHD}$ 환자에게서 콘서타 사용 시 대조군에 비 해 식욕감소, 수면문제, 입마름, 심계항진, 무월경, 성욕감소 등 이 대조군에 비해 더 많이 발생하였으나 이러한 부작용들은
대부분 단기간만 지속되었다. ${ }^{74,77)}$ 중추신경자극제를 성인 $\mathrm{ADHD}$ 의 치료를 위해 사용하였을 때 심혈관계에 미치는 영 향에 대해서는 아직 논란이 있다. 성인에서는 아동청소년과 는 달리 경계선 고혈압이나 심질환의 기왕력과 같이 심혈관계 의 문제를 가지고 있는 경우가 많으므로 메칠페니데이트 사 용 시 심혈관계 부작용에 주의하여야 한다. ${ }^{21,78)}$ 최근 25 64세 의 성인의 자료를 대상으로 한 후향적 연구에서 성인에서 처음 으로 $\mathrm{ADHD}$ 약물을 처방하는 경우 심각한 심혈관 문제의 위 험성을 증가시키지는 않는다고 보고하였다. ${ }^{79)}$

아토목세틴은 불안 및 틱이 동반된 성인 $\mathrm{ADHD}$ 에서 주의 력결핍과 과잉행동-충동성뿐만 아니라 불안 증상을 유의하 게 감소시키는 것으로 보고되고 있다. ${ }^{14,16,80)}$ 부작용으로는 입 마름, 불면, 오심, 식욕감소, 변비, 성욕저하, 어지러움, 발한 등 이 있으나 대부분 수 주 후에 감소하였으며, 경도의 혈압과 맥 박의 상승이 보고되었으나 임상적으로 유의한 정도는 아니었 다. ${ }^{16,81)}$ 그러나 아토목세틴이 심혈관계에 미치는 영향에 대해 서 아직 충분히 연구되지 않았으므로, 중추신경자극제와 유 사하게 고혈압이나 심혈관계 질환의 위험인자가 있는 성인에 서는 주의해서 처방하여야 한다.

부프로피온은 한국 및 미국 식품의약품안전처에서 성인 $\mathrm{ADHD}$ 에 대해 허가를 받지는 못하였으나, 최근에 시행된 5개 의 무작위 대조연구에서 유의미한 증상 감소를 보였다. ${ }^{78)}$ 부 프로피온의 부작용으로는 불면, 과민함, 졸림, 피로, 두통, 입 마름, 발한, 변비, 오심, 초조감 등이 있으며, 수축기 혈압과 맥 박이 통계적으로는 유의한 증가를 보였으나 임상적으로 유의 한 수준은 아니었다. ${ }^{78,82)}$ 흔하지는 않으나 뇌전증의 가능성이 있으므로 주의하여야 한다. 성인 $\mathrm{ADHD}$ 에서도 클로니딘이 증상을 호전시키는 데 도움이 된다는 연구가 있다. ${ }^{83}$ 또한 성 인 $\mathrm{ADHD}$ 환자를 대상으로 한 연구에서 모다피닐이 단기기 억, 시각기억, 공간계획, 각성, 정확성을 향상시키는 효과를 보 고한 연구도 있으나, ${ }^{84}$ 위약에 비해 유의미한 $\mathrm{ADHD}$ 증상 호 전이 없었다는 보고도 있어, ${ }^{85)} \mathrm{ADHD}$ 에서 모다피닐의 효과에 대해서는 추가적인 연구가 필요하다. 성인 $\mathrm{ADHD}$ 에서 삼환계 항우울제의 효과에 대한 연구는 거의 없으나, 한 연구에서 6 주 간 데시프라민(desipramine) 사용 시 성인 ADHD에서 위약군 에 비해 의미 있는 증상의 호전을 보인 바 있다. ${ }^{86}$

\section{동반 질환이 있는 경우의 약물치료}

\section{틱장애}

투렛장애를 포함한 틱장애는 $\mathrm{ADHD}$ 와 흔히 동반되며, $\mathrm{ADHD}$ 아동의 20 30\%에서 틱장애가 함께 나타난다. ${ }^{87-91)}$ 틱 이 아주 심한 경우를 제외하고는 틱 자체보다는 $\mathrm{ADHD}$ 증상 
이 환자의 기능 및 전반적 삶의 질을 저해하기 때문에,, ${ }^{92,93)}$ 틱 장애의 전반적 치료와 관리에 있어 $\mathrm{ADHD}$ 의 유무와 그 관리 를 고려해야 한다.

최근의 메타분석에 따르면 메칠페니데이트와 $\alpha 2$ 작용제, 아 토목세틴이 $\mathrm{ADHD}$ 와 틱장애가 있는 아동의 $\mathrm{ADHD}$ 증상 완 화에 효과적이다. ${ }^{94)}$ 뿐만 아니라, $\alpha 2$ 작용제와 아토목세틴은 경한 틱 증상을 다소 완화시키는 효과도 있었다. 중추신경자 극제 처방이 틱을 유발하거나 악화시킬 가능성에 대해서는 논란의 여지가 있으나, ${ }^{94)}$ 최근 연구에서는 대부분의 중추신경 자극제 처방이 틱을 악화시키지는 않는 것으로 보고되고 있 다. ${ }^{95,96)}$ 따라서, $\mathrm{ADHD}$ 증상이 심하고 아토목세틴이나 클로니 딘에 치료 반응이 나타나지 않으면 중추신경자극제를 사용할 수 있다. 이때, 중추신경자극제 치료 시작 후 최소 3개월간은 틱 증상이 새로 나타나거나 악화되지 않는지 모니터링해야 한 다. 혹시 틱이 악화된다면 리스페리돈(risperidone)과 같은 틱 치료제를 추가할 수도 있다.96,97)

\section{자폐스펙트럼장애(Autism spectrum disorder, ASD)}

자폐스펙트럼장애(autism spectrum disorder, ASD) 진단을 받은 환자의 58 $85 \%$ 가 $\mathrm{ADHD}$ 의 진단 기준을 만족하며, ${ }^{98)}$ $\mathrm{ADHD}$ 와 $\mathrm{ASD}$ 가 함께 있는 경우 $\mathrm{ASD}$ 만 있는 경우에 비해 실 행 기능과 적응행동의 손상이 심하고 행동장애 및 불안장애 가 더 높은 빈도로 나타난다. ${ }^{99,100)}$

$\mathrm{ASD}$ 와 $\mathrm{ADHD}$ 가 공존하는 경우 중추신경자극제가 과잉행 동 증상을 완화시키는 데 효과적이었으나, $\mathrm{ADHD}$ 단독으로 있는 경우보다는 치료 반응이 낮았으며, 사회적 위축이나 과 민성과 같은 부작용도 더 흔하게 나타났다. ${ }^{65)}$ 또한 $\mathrm{ASD}$ 아동 들은 의사소통에 어려움이 있어 부작용이 늦게 발견될 수 있 고, 심각한 부작용도 짜증 등의 비특이적인 형태로 나타날 수 있으므로 행동의 주의 깊은 관찰이 요구된다. $\mathrm{ADHD}$ 와 $\mathrm{ASD}$ 가 동반된 경우에서 아토목세틴이 $\mathrm{ADHD}$ 증상을 호전시킨다 는 보고도 있으나, ${ }^{101)}$ 아직 연구가 충분하지 않아 주의가 필요 하다. $\mathrm{ADHD}$ 와 $\mathrm{ASD}$ 가 동반된 환아에서 $\alpha 2$ 작용제가 수면과 $\mathrm{ADHD}$ 증상을 개선시켰다는 연구도 있고, ${ }^{102-104)}$ 위약 대비 유 의미한 효과는 없었다는 보고도 있어 추후 다른 연구의 결과 를 확인할 필요가 있다. ${ }^{104)}$

\section{뇌전증}

$\mathrm{ADHD}$ 아동에서는 경련이 동반되지 않는 뇌파 이상이 흔히 발견된다. ${ }^{105)}$ 뇌전증이 있는 아동에서도 주의집중력을 포함한 인지 기능의 저하가 흔히 관찰되며, $\mathrm{ADHD}$ 의 유병률이 일반 인구에 비해 2.5 5.5배 정도 높은 것으로 알려져 있다. ${ }^{106)}$ 일 반적으로 뇌전증을 가진 아동 중에서 항경련제가 충동 및 감
정 조절에 효과적이며, 경련을 조절함으로써 인지 기능에 긍정 적인 영향을 줄 수 있음이 보고되었다. ${ }^{107)}$ 그러나 항경련제 중 주의력에 부정적인 영향을 줄 수 있는 약물도 일부 있으므로, 주의력결핍 증상을 보이는 뇌전증 아동에서 항경련제의 영향 을 평가해야 한다. ${ }^{108)}$

뇌전증을 동반한 $\mathrm{ADHD}$ 아동청소년에서 중추신경자극제 는 $\mathrm{ADHD}$ 증상뿐 아니라 신경심리검사로 측정한 주의집중 능력과 삶의 질을 모두 개선하는 것으로 알려져 있다. 그러나 중추신경자극제가 뇌전증을 악화시킬 가능성에 대하여 논란 이 있어 왔다. 최근 연구에 따르면 뇌전증이 잘 조절될 때 중 추신경자극제를 추가하는 것은 안전한 것으로 알려져 있으 며, ${ }^{109)}$ 아토목세틴의 경우에도 경련을 악화시키지 않는 것으로 보고 되었다. ${ }^{110)}$ 하지만, 매일 경련이 나타나는 불안정한 상태 인 경우나 뇌파에서 간질이 지속적으로 나타나는 경우 등과 같은 뇌전증이 잘 조절되지 않는 상황에서의 중추신경자극제 사용은 상당한 주의를 기울여야 한다. ${ }^{111}$

\section{치료순응도 및 장기치료}

\section{치료순응도}

$\mathrm{ADHD}$ 는 소아기에 발병하여 반수 이상이 성인기까지 증상 이 지속될 수 있는 지속성 또는 만성질환이라고 알려져 있으 므로, 치료 개시 시점부터 장기 계획을 세워야 할 것이다. 특히 성인기에 처음 $\mathrm{ADHD}$ 를 진단받고 치료를 시작하는 경우, 평생 지속될 가능성이 매우 높으므로 신중하게 치료 개시 및 유지 계획을 설계해야 한다. $\mathrm{ADHD}$ 의 치료 유형은 소아청소년기 에 진단 및 치료 후 치료를 종결한 경우가 아니라면 다음과 같이 세 가지로 나눠 볼 수 있다. ${ }^{112)}$ 1) 소아청소년기에 치료를 시작하였고, 성인기에도 지속치료가 필요한 경우, 2) 소아청소 년기에 치료 도중 탈락하였으나 성인기에 계속 치료가 필요한 경우, 3) 소아청소년기에 진단 및 치료 경력이 없으나 성인기 에 치료 필요성을 확인한 경우 등이다. 우리나라 $\mathrm{ADHD}$ 유병 률 연구 중 서울시 초등학생 약 2400명을 대상으로 한 연구에 서 $6.5 \%$ 의 유병률을 보고하였고, ${ }^{113)}$ 국민건강보험심사평가원 의 2008 2011년 기간 동안 18세 이하 인구 자료 분석에서 매 년 신규 치료율은 평균 $0.248 \%$ 였다. ${ }^{114)}$ 즉, 우리나라의 경우 여전히 조기 진단율 및 개입 비율이 낮으므로 위에서 말한 세 번째 치료 유형이 가장 많을 것으로 예상되므로 소아청소년기 의 진단율 및 치료순응도를 높일 수 있는 대책이 시급하다.

치료순응도에 영향을 끼치는 환자측 요인 중 치료 개시 당 시 나이가 특히 중요하다. ${ }^{115)}$ 우리나라는 2016년 9월 이전까지 19 세 이상 환자군의 건강보험적용이 불허되었던 까닭에 성인 환자군의 $\mathrm{ADHD}$ 약물치료순응도나 현황을 알 수 있는 자료 
가 없으나, Bhang 등 ${ }^{116)}$ 의 건강보험심사평가원 자료 분석 결과 에서 6 18세까지 연령에 따른 치료순응도의 유의한 차이가 있 었던 점을 성인환자 진료 시 고려해야 한다. 18 세 이하 환자군 에서 치료율이 가장 높은 연령대는 7 9세로 $35.6 \%$ 이며, 연령이 높아지면서 16 18세 구간은 7.6\%로 낮아진다. 이러한 현상이 약물치료로 증상이 현저히 호전되어 치료를 종료한 것인지, 다 른 변인들 때문에 치료가 조기 종료된 것인지 확인이 필요하다. 영국의 의료 전달 체계에서 소아청소년기 이후 성인기로 전환 되는 과정에서 의료기관 이용 방법이 달라지고 기존 치료군의 치료지속률이 현저히 낮아지는 '황혼기 구역(twilight zone) $)^{117 \text { ) }}$ 이 출현하는 것을 고려하면, 청소년기 이후 치료율 저하는 청 소년기 자체 특성과도 관련이 있을 수 있다. 즉, 소아청소년기 에 치료를 시작하더라도 성인기로 이행되는 과정에서 치료순 응도가 낮아지는 현상이 발행하는 것이다. 연령 요인 이외에도 치료순응도를 평가, 측정할 때 다양한 요인들을 고려해야 하 지만 적용 기준에 따라 큰 차이가 생길 수 있다. 즉, 치료기관 (개인의원, 종합병원, 대학병원 등), 약물 종류 및 작용방식(서 방형, 속효성), 성별, 공존질환 여부, 처방의사의 전문과목 등 의 변수를 확인해야 한다. ${ }^{118)}$

DSM-IV-TR ${ }^{119)}$ 진단 체계에서는 7세 이전 증상 기준이 성 인기 ADHD 진단을 어렵게 만드는 요인이었으나, $\mathrm{DSM}-5^{120)}$ 에서 아동기 증상 연령 기준을 12 세로 높이면서 성인 $\mathrm{ADHD}$ 진단 가능성이 높아졌고, 그에 따라 성인 $\mathrm{ADHD}$ 에 대한 관심 이 크게 늘었다. ${ }^{121)}$ 성인기가 되면 $\mathrm{ADHD}$ 치료 필요성은 개인 과 가족의 문제를 넘어 환자가 살고 있는 지역사회는 물론 사 회 전체 문제로 확대될 수 있다. 상대적으로 낮은 학력, 잦은 직업 교체 외에도 결혼생활, 교통사고 등의 문제가 두드러진 다. ${ }^{122)} \mathrm{ADHD}$ 증상은 사망원인 연구에서도 큰 비중을 차지한 다. 성인의 사망원인 중 사고사가 차지하는 비율이 $\mathrm{ADHD}$ 가 아 닌 일반 인구에서 $4.3 \%$ 인데에 비해, $\mathrm{ADHD}$ 인구의 사고사 비 율은 $13.2 \%$ 로 월등히 높고, 연구자에 따라 다르기는 하지만 일반 인구에 비해 $\mathrm{ADHD}$ 사망률은 1.78 배 ${ }^{123)}$ 내지 4.23배 ${ }^{124}$ 정 도 높다. Kooij 등 ${ }^{125}$ 은 55세 이상 인구에서도 $3 \%$ 이상 유병률 을 보이며 젊은 층에서 나타나는 불안, 우울 및 사회적 장애가 동반된다고 하였다. 이러한 자료는 $\mathrm{ADHD}$ 의 조기 개입, 치료 순응도 향상 및 장기 치료 필요성을 반영한다.

\section{장기치료}

이러한 필요에도 불구하고 사회 전반에 광범위하게 퍼져 있 는 $\mathrm{ADHD}$ 약물치료에 대한 오해와 편견이 치료순응도와 유지 치료를 어렵게 만든다. ${ }^{126)}$ 따라서 장기 치료유지를 위한 방안 으로 중요한 것은 첫째, $\mathrm{ADHD}$ 및 약물치료에 대한 교육이 다. ${ }^{115)}$ 약물치료 개시 이전에 약물에 대한 정보, 약물치료의 이
유, 진행 과정, 부작용과 대처 요령, 정기적 평가 등에 대한 정 보를 제공해야 한다. 둘째, 환자 개인을 대상으로 맞춤형 약물 치료 전략을 세운다. 약물치료에 대한 환자 가족 및 주변 인물 들의 부정적 영향을 낮추거나 예방해야 할 것이고, 약물 효과 를 최대화하고 부작용을 최소화할 수 있어야 한다. 특히 약물 복용 후 정서적 둔감은 치료 탈락의 주 요인이므로 관심을 기 울여야 한다. 셋째, 약물치료를 성공적으로 유지하기 위해서 는 직업, 생활기술(운전 등), 대인관계 등 여러 삶의 영역에서 지속되는 잔존 증상 개선을 위해 비약물적 치료를 함께 하는 것이 중요하다. ${ }^{127)}$

이와 더불어 임상 실제에서 $\mathrm{ADHD}$ 치료자가 가장 많이 받 는 질문 중 하나가 약물치료를 언제까지 해야 하고, 치료를 종 결하는 기준이 무엇인가 하는 것이다. 약물치료의 경우 약물 종류에 따른 효과 발현 시기에 대한 연구는 많지만, 치료기간 을 결정하는 기준은 분명하지 않다. 미국 소아청소년정신의학 회에서는 1년에 한 번 정도 스트레스가 적은 방학 기간 등을 이용하여 약물 중단 후 반응을 평가하도록 권장한다. ${ }^{35)}$ 그러 나 임상 현장에서는 실제로 약물치료를 1년간 지속하는 것도 쉽지 않다. Hong 등 ${ }^{128}$ 이 건강보험심사평가원 자료를 분석한 결과, 우리나라 18 세 이하 $\mathrm{ADHD}$ 환자의 약 40\%가 약물치료 개시 후 최초 6 개월 이내에 탈락하며, 36 개월 후 치료 유지율은 약 23.1\%였다. 치료순응도를 평가하는 mean possession ratio 기준을 0.8 로 엄격하게 적용하면 36개월 후 치료 유지율은 $9.8 \%$ 로 더 낮아진다. 우리나라와 유사한 전 국민 의료보험 제 도를 채택하고 있는 대만의 경우도 ADHD 치료 유병률은 늘 고 있으나, 약물치료 개시 후 1 년 이내에 반 이상이 탈락한다. ${ }^{129}$ Hwangbo 등 ${ }^{130)}$ 은 19 세 미만 인구의 정신장애에 대한 건강보 험심사평가원 자료 분석에서 $\mathrm{ADHD}$ 진단유병률과 치료율이 청소년기로 접어들면 현저히 낮아지고, 남녀 모두 불안장애와 우울증 진단이 급격히 늘어난다고 보고하였다. 정신장애의 분포가 실제로 달라지는 것인지, $\mathrm{ADHD}$ 관련 공존증상이 다 른 장애로 진단받는 것인지 감별진단이 필요하다. 성인기에는 특히 우울증, 인격장애, 물질남용 등 드러난 공존장애가 일차 진단이 될 가능성이 높다. ${ }^{122}$ 성인환자에서 우울증, 자기애적 또는 경계성 인격장애, 물질남용 등이 공존하는 경우 기저의 $\mathrm{ADHD}$ 를 의심해야 하는 이유이다. 정확한 평가와 진단을 통 해 기저의 $\mathrm{ADHD}$ 를 진단하고, 그에 맞는 치료를 시행함으로 써 유지치료가 가능하게 될 것이다.

유지치료를 위해 고려해야 할 것 중의 하나로 $\mathrm{ADHD}$ 치료 탈 락률이 높은 이유가 치료 자체에 대한 반발이라기보다 ADHD 증상 특성일 가능성을 생각해야 한다. ${ }^{131)}$ 과거 학창 시절 수업 에 결석하는 빈도가 높았던 경우 성인이 되어서 약물 복용을 건너뛰고 외래 방문 약속을 잊어서 치료 탈락될 확률이 더 높 
다. 즉, 학력이 낮은 것이 치료율이 낮은 것과 연관이 있다. 불 안 및 우울 같은 기분 증상도 치료 탈락률이 높아지는 데 기 여한다. 아형 중 부주의형이 다른 유형에 비해 탈락률이 높다. 이를 극복하고 약물치료를 성공적으로 수행하기 위해서는 성 인에서도 의사-환자 관계가 중요하며, 적절한 치료 조력 체계 가 필요하다. ${ }^{112)}$

\section{결 론}

임상 실제에서 $\mathrm{ADHD}$ 약물치료 시 다음과 같은 내용을 권 고사항으로 제시한다.

권고사항 $1 . \mathrm{ADHD}$ 의 치료 계획은 증상과 기능에 대하여 종합적으로 평가한 후 이루어지는 것이 바람직하다.

권고사항 2. $\mathrm{ADHD}$ 의 약물치료는 일차적으로 중추신경자 극제와 아토목세틴을 사용하는 것을 추천한다.

권고사항 3. 일차 치료약제의 효과가 없거나 부작용으로 인 해 약물 교체가 필요한 경우 다른 중추신경자극제나 아토목 세틴, $\alpha 2$ 작용제로 교체하거나 병합요법을 실시한다.

권고사항 4. 약물치료 중에 치료제와 관련된 부작용의 발 생 및 악화에 대하여 주의 깊게 관찰하고 대처한다.

권고사항 5. 학령전기 아동과 성인에서는 $\mathrm{ADHD}$ 의 약물치 료에서 연령에 따른 특징과 부작용을 고려한다.

권고사항 6. 동반이환이 있는 경우에는 $\mathrm{ADHD}$ 의 증상과 기 능 저하에 대해서 평가하고 약물치료의 효과와 부작용을 평가 할 때 동반이환의 영향을 고려한다.

권고사항 7. $\mathrm{ADHD}$ 증상이 남아 있고 기능장애가 있는 경 우 치료를 지속하는 것을 권한다.

권고사항 8. 약물치료와 함께 정신사회적 치료의 필요성에 대하여 고려한다.

중심 단어:주의력결핍 과잉행동장애; 중추신경자극제; 비중추신경자극제; 약물치료.

\section{Conflicts of Interest}

The authors have no financial conflicts of interest.

\section{REFERENCES}

1) Hunt RD, Arnsten AF, Asbell MD. An open trial of guanfacine in the treatment of attention-deficit hyperactivity disorder. J Am Acad Child Adolesc Psychiatry 1995;34:50-54.

2) Greenhill LL, Pliszka S, Dulcan MK, Bernet W, Arnold V, Beitchman J, et al. Practice parameter for the use of stimulant medications in the treatment of children, adolescents, and adults. J Am Acad Child Adolesc Psychiatry 2002;41(2 Suppl):26S-49S.

3) Subcommittee on Attention-Deficit/Hyperactivity Disorder; Steering Committee on Quality Improvement and Management, Wolraich $M$, Brown L, Brown RT, DuPaul G, et al. ADHD: clinical practice guideline for the diagnosis, evaluation, and treatment of attention-deficit/hyperactivity disorder in children and adolescents. Pediatrics 2011;128:1007-1022.

4) Kim B, Park E. An observation multi-center study for evaluation of efficacy, safety and parental satisfaction of methylphenidateOROS in children with ADHD. J Korean Acad Child Adolesc Psychiatry 2005;16:279-285.

5) Kim Y, Shin MS, Kim JW, Yoo HJ, Cho SC, Kim BN. Neurocognitive effects of switching from methylphenidate-IR to OROSmethylphenidate in children with ADHD. Hum Psychopharmacol 2009;24:95-102.

6) Kim E, Cheon KA, Joung YS, Kim JY, Song DH. The relationship between symptomatic and functional changes of Korean children and adolescents with attention-deficit/hyperactivity disorder treated with osmotic-controlled release oral delivery system-methylphenidate. Clin Neuropharmacol 2015;38:30-35.

7) Hwang JW, Kim B, Kim Y, Kim TH, Seo WS, Shin DW, et al. Methylphenidate-osmotic-controlled release oral delivery system treatment reduces parenting stress in parents of children and adolescents with attention-deficit/hyperactivity disorder. Hum Psychopharmacol 2013;28:600-607.

8) Yoo HK, Park S, Wang HR, Lee JS, Kim K, Paik KW, et al. Effect of methylphenidate on the quality of life in children with epilepsy and attention deficit hyperactivity disorder: and open-label study using an osmotic-controlled release oral delivery system. Epileptic Disord 2009;11:301-308.

9) Hwang JW, Kim BN, Cho SC. Compliance study of methylphenidate IR in the treatment of ADHD. J Korean Acad Chid Adolesc Psychiatry 2004; 15:160-167.

10) Armstrong RB, Damaraju CV, Ascher S, Schwarzman L, O'Neill J, Starr HL. Time course of treatment effect of OROS $®$ methylphenidate in children with ADHD. J Atten Disord 2012;16:697-705.

11) Childress A, Sallee FR. The use of methylphenidate hydrochloride extended-release oral suspension for the treatment of ADHD. Expert Rev Neurother 2013;13:979-988.

12) Maldonado R. Comparison of the pharmacokinetics and clinical efficacy of new extended-release formulations of methylphenidate. Expert Opin Drug Metab Toxicol 2013;9:1001-1014.

13) Brams M, Mao AR, Doyle RL. Onset of efficacy of long-acting psychostimulants in pediatric attention-deficit/hyperactivity disorder. Postgrad Med 2008;120:69-88.

14) Michelson D, Allen AJ, Busner J, Casat C, Dunn D, Kratochvil C, et al. Once-daily atomoxetine treatment for children and adolescents with attention deficit hyperactivity disorder: a randomized, placebo-controlled study. Am J Psychiatry 2002;159:1896-1901.

15) Michelson D, Faries D, Wernicke J, Kelsey D, Kendrick K, Sallee FR, et al. Atomoxetine in the treatment of children and adolescents with attention-deficit/hyperactivity disorder: a randomized, placebo-controlled, dose-response study. Pediatrics 2001;108:E83.

16) Michelson D, Adler L, Spencer T, Reimherr FW, West SA, Allen AJ, et al. Atomoxetine in adults with ADHD: two randomized, placebo-controlled studies. Biol Psychiatry 2003;53:112-120.

17) Miller MC. What is the significance of the new warnings about suicide risk with strattera? Harv Ment Health Lett 2005;22:8.

18) Kratochvil CJ, Heiligenstein JH, Dittmann R, Spencer TJ, Biederman J, Wernicke J, et al. Atomoxetine and methylphenidate treatment in children with ADHD: a prospective, randomized, open-label trial. J Am Acad Child Adolesc Psychiatry 2002;41:776-784.

19) Newcorn JH, Kratochvil CJ, Allen AJ, Casat CD, Ruff DD, Moore RJ, et al. Atomoxetine and osmotically released methylphenidate for the treatment of attention deficit hyperactivity disorder: acute comparison and differential response. Am J Psychiatry 2008;165: 721-730.

20) Biederman J, Spencer TJ, Newcorn JH, Gao H, Milton DR, Feldman PD, et al. Effect of comorbid symptoms of oppositional defiant disorder on responses to atomoxetine in children with ADHD: 
a meta-analysis of controlled clinical trial data. Psychopharmacology (Berl) 2007;190:31-41.

21) Kratochvil CJ, Newcorn JH, Arnold LE, Duesenberg D, Emslie GJ, Quintana H, et al. Atomoxetine alone or combined with fluoxetine for treating ADHD with comorbid depressive or anxiety symptoms. J Am Acad Child Adolesc Psychiatry 2005;44:915-924.

22) Cho S, Lee SI, Yoo H, Song DH, Ahn DH, Shin DW, et al. A randomized, open-label assessment of response to various doses of atomoxetine in korean pediatric outpatients with attention-deficit/hyperactivity disorder. Psychiatry Investig 2011;8:141-148.

23) Briars L, Todd T. A review of pharmacological management of attention-deficit/hyperactivity disorder. J Pediatr Pharmacol Ther 2016;21:192-206.

24) Posey DJ, McDougle CJ. Guanfacine and guanfacine extended release: treatment for ADHD and related disorders. CNS Drug Rev 2007:13:465-474

25) Conners CK, Casat CD, Gualtieri CT, Weller E, Reader M, Reiss A, et al. Bupropion hydrochloride in attention deficit disorder with hyperactivity. J Am Acad Child Adolesc Psychiatry 1996;35:13141321.

26) Maneeton N, Maneeton B, Intaprasert S, Woottiluk P. A systematic review of randomized controlled trials of bupropion versus methylphenidate in the treatment of attention-deficit/hyperactivity disorder. Neuropsychiatr Dis Treat 2014;10:1439-1449.

27) Stuhec M, Munda B, Svab V, Locatelli I. Comparative efficacy and acceptability of atomoxetine, lisdexamfetamine, bupropion and methylphenidate in treatment of attention deficit hyperactivity disorder in children and adolescents: a meta-analysis with focus on bupropion. J Affect Disord 2015;178:149-159.

28) Greenhill LL, Biederman J, Boellner SW, Rugino TA, Sangal RB, Earl CQ, et al. A randomized, double-blind, placebo-controlled study of modafinil film-coated tablets in children and adolescents with attention-deficit/hyperactivity disorder. J Am Acad Child Adolesc Psychiatry 2006;45:503-511.

29) Kahbazi M, Ghoreishi A, Rahiminejad F, Mohammadi MR, Kamalipour A, Akhondzadeh S. A randomized, double-blind and placebo-controlled trial of modafinil in children and adolescents with attention deficit and hyperactivity disorder. Psychiatry Res 2009;168:234-237.

30) Biederman J, Swanson JM, Wigal SB, Boellner SW, Earl CQ, Lopez FA; Modafinil ADHD Study Group. A comparison of oncedaily and divided doses of modafinil in children with attentiondeficit/hyperactivity disorder: a randomized, double-blind, and placebo-controlled study. J Clin Psychiatry 2006;67:727-735.

31) Canadian ADHD Resource Alliance. Canadian ADHD practice guidelines [cited 2016 Sep 1]. Available from: http://www.caddra. $\mathrm{ca} /$ practice-guidelines/download.

32) Ministry of Health Library. New Zealand guidelines for the assessment and treatment of attention-deficit/hyperactivity disorder [cited 2016 Sep 20]. Available from: http://www.moh.govt.nz/ NoteBook/nbbooks.nsf/0/26ADED701C00CA90CC256A980078 2552?opendocument.

33) Perrin JM, Stein MT, Amler RW, Blondis TA, Feldman HM, Meyer BP, et al. Clinical practice guideline: treatment of the school-aged child with attention-deficit/hyperactivity disorder. Pediatrics 2001; 108:1033-1044.

34) Yoo HJ, Yang SJ, Shin D, Kang H, Kim BN, Kim JH, et al. The Korean practice parameter for the treatment of attention-deficit hyperactivity disorder (III)-pharmacologic treatment. J Korean Acad Child Adolesc Psychiatry 2007;18:16-25.

35) American Academy of Child, Adolescent Psychiatry, American Psychiatric Association. ADHD parents medication guide [cited 2016 Sep 1]. Available from: http://www.aacap.org/aacap/press/ press_releases/2013/aacap_announces_new_parents_medication_ guide_on_adhd.aspx.
36) Brown TE. ADHD comorbidities: handbook for ADHD complications in children and adults. Washington, DC: American Psychiatric Pub;2009.

37) Daviss WB, Scott J. A chart review of cyproheptadine for stimulant-induced weight loss. J Child Adolesc Psychopharmacol 2004; 14:65-73.

38) Perrin JM, Friedman RA, Knilans TK; Black Box Working Group; Section on Cardiology and Cardiac Surgery. Cardiovascular monitoring and stimulant drugs for attention-deficit/hyperactivity disorder. Pediatrics 2008;122:451-453.

39) McCarthy S, Cranswick N, Potts L, Taylor E, Wong IC. Mortality associated with attention-deficit hyperactivity disorder (ADHD) drug treatment: a retrospective cohort study of children, adolescents and young adults using the general practice research database. Drug Saf 2009;32:1089-1096.

40) Gould MS, Walsh BT, Munfakh JL, Kleinman M, Duan N, Olfson M, et al. Sudden death and use of stimulant medications in youths. Am J Psychiatry 2009;166:992-1001.

41) Cooper WO, Habel LA, Sox CM, Chan KA, Arbogast PG, Cheetham TC, et al. ADHD drugs and serious cardiovascular events in children and young adults. N Engl J Med 2011;365:1896-1904.

42) Shin JY, Roughead EE, Park BJ, Pratt NL. Cardiovascular safety of methylphenidate among children and young people with attention-deficit/hyperactivity disorder (ADHD): nationwide self controlled case series study. BMJ 2016;353:i2550.

43) Faraone SV, Biederman J, Morley CP, Spencer TJ. Effect of stimulants on height and weight: a review of the literature. J Am Acad Child Adolesc Psychiatry 2008;47:994-1009.

44) Kim HW, Kim SO, Shon S, Lee JS, Lee HJ, Choi JH. Effect of methylphenidate on height and weight in Korean children and adolescents with attention-deficit/hyperactivity disorder: a retrospective chart review. J Child Adolesc Psychopharmacol 2014;24: 448-453.

45) Ahn HS. Hong Chang Yee textbook of pediatrics. Seoul: Mirae N Co., Ltd.;2012.

46) Sullivan MA, Rudnik-Levin F. Attention deficit/hyperactivity disorder and substance abuse. Diagnostic and therapeutic considerations. Ann N Y Acad Sci 2001;931:251-270.

47) Hammerness P, Joshi G, Doyle R, Georgiopoulos A, Geller D, Spencer T, et al. Do stimulants reduce the risk for cigarette smoking in youth with attention-deficit hyperactivity disorder? A prospective, long-term, open-label study of extended-release methylphenidate. J Pediatr 2013;162:22-27.e2.

48) Biederman J, Monuteaux MC, Spencer T, Wilens TE, Macpherson HA, Faraone SV. Stimulant therapy and risk for subsequent substance use disorders in male adults with ADHD: a naturalistic controlled 10-year follow-up study. Am J Psychiatry 2008;165:597-603.

49) Lichtenstein P, Halldner L, Zetterqvist J, Sjölander A, Serlachius E, Fazel S, et al. Medication for attention deficit-hyperactivity disorder and criminality. N Engl J Med 2012;367:2006-2014.

50) Greenhill LL, Pliszka S, Dulcan MK, Bernet W, Arnold V, Beitchman J, et al. Practice parameter for the use of stimulant medications in the treatment of children, adolescents, and adults. J Am Acad Child Adolesc Psychiatry 2002;41(2 Suppl):26S-49S.

51) Cheng JY, Chen RY, Ko JS, Ng EM. Efficacy and safety of atomoxetine for attention-deficit/hyperactivity disorder in children and adolescents-meta-analysis and meta-regression analysis. Psychopharmacology (Berl) 2007;194:197-209.

52) Greenhill LL, Newcorn JH, Gao H, Feldman PD. Effect of two different methods of initiating atomoxetine on the adverse event profile of atomoxetine. J Am Acad Child Adolesc Psychiatry 2007;46: 566-572.

53) Wietecha LA, Ruff DD, Allen AJ, Greenhill LL, Newcorn JH. Atomoxetine tolerability in pediatric and adult patients receiving different dosing strategies. J Clin Psychiatry 2013;74:1217-1223. 
54) Reed VA, Buitelaar JK, Anand E, Day KA, Treuer T, Upadhyaya HP, et al. The safety of atomoxetine for the treatment of children and adolescents with attention-deficit/hyperactivity disorder: a comprehensive review of over a decade of research. CNS Drugs 2016;30:603-628.

55) Maneeton N, Maneeton B, Srisurapanont M, Martin SD. Bupropion for adults with attention-deficit hyperactivity disorder: metaanalysis of randomized, placebo-controlled trials. Psychiatry Clin Neurosci 2011;65:611-617.

56) Kratochvil CJ, Wilens TE, Greenhill LL, Gao H, Baker KD, Feldman PD, et al. Effects of long-term atomoxetine treatment for young children with attention-deficit/hyperactivity disorder. J Am Acad Child Adolesc Psychiatry 2006;45:919-927.

57) Spencer TJ, Newcorn JH, Kratochvil CJ, Ruff D, Michelson D, Biederman J. Effects of atomoxetine on growth after 2-year treatment among pediatric patients with attention-deficit/hyperactivity disorder. Pediatrics 2005;116:e74-e80.

58) Camporeale A, Day KA, Ruff D, Arsenault J, Williams D, Kelsey DK. Profile of sexual and genitourinary treatment-emergent adverse events associated with atomoxetine treatment: a pooled analysis. Drug Saf 2013;36:663-671.

59) Croxtall JD. Clonidine extended-release in attention-deficit hyperactivity disorder: profile report. CNS Drugs 2012;26:277-279.

60) Kollins SH, Jain R, Brams M, Segal S, Findling RL, Wigal SB, et al. Clonidine extended-release tablets as add-on therapy to psychostimulants in children and adolescents with ADHD. Pediatrics 2011;127:e1406-e1413.

61) Jain R, Segal S, Kollins SH, Khayrallah M. Clonidine extendedrelease tablets for pediatric patients with attention-deficit/hyperactivity disorder. J Am Acad Child Adolesc Psychiatry 2011;50: 171-179.

62) Spencer T, Biederman J, Steingard R, Wilens T. Bupropion exacerbates tics in children with attention-deficit hyperactivity disorder and Tourette's syndrome. J Am Acad Child Adolesc Psychiatry 1993;32:211-214.

63) Greenhill L, Kollins S, Abikoff H, McCracken J, Riddle M, Swanson J, et al. Efficacy and safety of immediate-release methylphenidate treatment for preschoolers with ADHD. J Am Acad Child Adolesc Psychiatry 2006;45:1284-1293.

64) Abikoff HB, Vitiello B, Riddle MA, Cunningham C, Greenhill LL, Swanson JM, et al. Methylphenidate effects on functional outcomes in the Preschoolers with attention-deficit/hyperactivity disorder treatment study (PATS). J Child Adolesc Psychopharmacol 2007;17:581-592.

65) Greenhill LL, Swanson JM, Vitiello B, Davies M, Clevenger W, Wu $\mathbf{M}$, et al. Impairment and deportment responses to different methylphenidate doses in children with ADHD: the MTA titration trial. J Am Acad Child Adolesc Psychiatry 2001;40:180-187.

66) Wigal SB, Gupta S, Greenhill L, Posner K, Lerner M, Steinhoff K, et al. Pharmacokinetics of methylphenidate in preschoolers with attention-deficit/hyperactivity disorder. J Child Adolesc Psychopharmacol 2007;17:153-164.

67) Ghuman JK, Aman MG, Ghuman HS, Reichenbacher T, Gelenberg A, Wright R, et al. Prospective, naturalistic, pilot study of open-label atomoxetine treatment in preschool children with attention-deficit/hyperactivity disorder. J Child Adolesc Psychopharmacol 2009;19:155-166.

68) Vitiello B, Lazzaretto D, Yershova K, Abikoff H, Paykina N, McCracken JT, et al. Pharmacotherapy of the preschool ADHD treatment study (PATS) children growing up. J Am Acad Child Adolesc Psychiatry 2015;54:550-556.

69) Park S, Cho MJ, Chang SM, Jeon HJ, Cho SJ, Kim BS, et al. Prevalence, correlates, and comorbidities of adult ADHD symptoms in Korea: results of the Korean epidemiologic catchment area study. Psychiatry Res 2011;186:378-383.
70) Gibbins C, Weiss M. Clinical recommendations in current practice guidelines for diagnosis and treatment of ADHD in adults. Curr Psychiatry Rep 2007;9:420-426.

71) Spencer T, Biederman J, Wilens T, Doyle R, Surman C, Prince J, et al. A large, double-blind, randomized clinical trial of methylphenidate in the treatment of adults with attention-deficit/hyperactivity disorder. Biol Psychiatry 2005;57:456-463.

72) Biederman J, Mick E, Surman C, Doyle R, Hammerness P, Harpold T, et al. A randomized, placebo-controlled trial of OROS methylphenidate in adults with attention-deficit/hyperactivity disorder. Biol Psychiatry 2006;59:829-835.

73) Medori R, Ramos-Quiroga JA, Casas M, Kooij JJ, Niemelä A, Trott GE, et al. A randomized, placebo-controlled trial of three fixed dosages of prolonged-release OROS methylphenidate in adults with attention-deficit/hyperactivity disorder. Biol Psychiatry 2008;63:981-989.

74) Rösler M, Fischer R, Ammer R, Ose C, Retz W. A randomised, placebo-controlled, 24-week, study of low-dose extended-release methylphenidate in adults with attention-deficit/hyperactivity disorder. Eur Arch Psychiatry Clin Neurosci 2009;259:120-129.

75) Marchant BK, Reimherr FW, Halls C, Williams ED, Strong RE. OROS methylphenidate in the treatment of adults with ADHD: a 6-month, open-label, follow-up study. Ann Clin Psychiatry 2010;22: 196-204.

76) Wender PH, Reimherr FW, Marchant BK, Sanford ME, Czajkowski LA, Tomb DA. A one year trial of methylphenidate in the treatment of ADHD. J Atten Disord 2011;15:36-45.

77) Adler LA, Orman C, Starr HL, Silber S, Palumbo J, Cooper K, et al. Long-term safety of OROS methylphenidate in adults with attention-deficit/hyperactivity disorder: an open-label, dose-titration, 1-year study. J Clin Psychopharmacol 2011;31:108-114.

78) Wilens TE, Haight BR, Horrigan JP, Hudziak JJ, Rosenthal NE, Connor DF, et al. Bupropion XL in adults with attention-deficit/ hyperactivity disorder: a randomized, placebo-controlled study. Biol Psychiatry 2005;57:793-801.

79) Habel LA, Cooper WO, Sox CM, Chan KA, Fireman BH, Arbogast PG, et al. ADHD medications and risk of serious cardiovascular events in young and middle-aged adults. JAMA 2011;306: 2673-2683.

80) Adler LA, Liebowitz M, Kronenberger W, Qiao M, Rubin R, Hollandbeck $\mathbf{M}$, et al. Atomoxetine treatment in adults with attentiondeficit/hyperactivity disorder and comorbid social anxiety disorder. Depress Anxiety 2009;26:212-221.

81) Adler LA, Spencer T, Brown TE, Holdnack J, Saylor K, Schuh K, et al. Once-daily atomoxetine for adult attention-deficit/hyperactivity disorder: a 6-month, double-blind trial. Clin Psychopharmacol 2009;29:44-50.

82) Reimherr FW, Hedges DW, Strong RE, Marchant BK, Williams ED. Bupropion SR in adults with ADHD: a short-term, placebocontrolled trial. Neuropsychiatr Dis Treat 2005;1:245-251.

83) Kooij JJ, Aeckerlin LP, Buitelaar JK. [Functioning, comorbidity and treatment of 141 adults with attention deficit hyperactivity disorder (ADHD) at a psychiatric outpatient department]. Ned Tijdschr Geneeskd 2001;145:1498-1501.

84) Turner DC, Clark L, Dowson J, Robbins TW, Sahakian BJ. Modafinil improves cognition and response inhibition in adult attention-deficit/hyperactivity disorder. Biol Psychiatry 2004;55: 1031-1040.

85) Arnold VK, Feifel D, Earl CQ, Yang R, Adler LA. A 9-week, randomized, double-blind, placebo-controlled, parallel-group, dosefinding study to evaluate the efficacy and safety of modafinil as treatment for adults with ADHD. J Atten Disord 2014;18:133-144.

86) Wilens TE, Biederman J, Prince J, Spencer TJ, Faraone SV, Warburton R, et al. Six-week, double-blind, placebo-controlled study of desipramine for adult attention deficit hyperactivity disorder. 
Am J Psychiatry 1996;153:1147-1153.

87) Spencer T, Biederman J, Harding M, O’Donnell D, Wilens T, Faraone S, et al. Disentangling the overlap between Tourette's disorder and ADHD. J Child Psychol Psychiatry 1998;39:1037-1044.

88) The MTA Cooperative Group. A 14-month randomized clinical trial of treatment strategies for attention-deficit/hyperactivity disorder. The MTA Cooperative Group. Multimodal treatment study of children with ADHD. Arch Gen Psychiatry 1999;56:1073-1086.

89) Pliszka SR. Patterns of psychiatric comorbidity with attention-deficit/hyperactivity disorder. Child Adolesc Psychiatr Clin N Am 2000;9:525-540, vii.

90) The MTA Cooperative Group. Moderators and mediators of treatment response for children with attention-deficit/hyperactivity disorder: the multimodal treatment study of children with attention-deficit/hyperactivity disorder. Arch Gen Psychiatry 1999;56: 1088-1096.

91) Roessner V, Becker A, Banaschewski T, Rothenberger A. Psychopathological profile in children with chronic tic disorder and coexisting ADHD: additive effects. J Abnorm Child Psychol 2007; 35:79-85.

92) Spencer TJ, Biederman J, Faraone S, Mick E, Coffey B, Geller D, et al. Impact of tic disorders on ADHD outcome across the life cycle: findings from a large group of adults with and without ADHD. Am J Psychiatry 2001;158:611-617.

93) Peterson BS, Pine DS, Cohen P, Brook JS. Prospective, longitudinal study of tic, obsessive-compulsive, and attention-deficit/hyperactivity disorders in an epidemiological sample. J Am Acad Child Adolesc Psychiatry 2001;40:685-695.

94) Bloch MH, Panza KE, Landeros-Weisenberger A, Leckman JF. Meta-analysis: treatment of attention-deficit/hyperactivity disorder in children with comorbid tic disorders. J Am Acad Child Adolesc Psychiatry 2009;48:884-893.

95) Pringsheim T, Steeves T. Pharmacological treatment for attention deficit hyperactivity disorder (ADHD) in children with comorbid tic disorders. Cochrane Database Syst Rev 2011;(4):CD007990.

96) Rizzo R, Gulisano M, Calì PV, Curatolo P. Tourette syndrome and comorbid ADHD: current pharmacological treatment options. Eur J Paediatr Neurol 2013;17:421-428.

97) Roessner V, Plessen KJ, Rothenberger A, Ludolph AG, Rizzo R, Skov L, et al. European clinical guidelines for Tourette syndrome and other tic disorders. Part II: pharmacological treatment. Eur Child Adolesc Psychiatry 2011;20:173-196.

98) Geller B, Guttmacher LB, Bleeg M. Coexistence of childhood onset pervasive developmental disorder and attention deficit disorder with hyperactivity. Am J Psychiatry 1981;138:388-389.

99) Guttmann-Steinmetz S, Gadow KD, DeVincent CJ, Crowell J. Anxiety symptoms in boys with autism spectrum disorder, attention-deficit hyperactivity disorder, or chronic multiple tic disorder and community controls. J Autism Dev Disord 2010;40:1006-1016.

100) Corbett BA, Constantine LJ, Hendren R, Rocke D, Ozonoff S. Examining executive functioning in children with autism spectrum disorder, attention deficit hyperactivity disorder and typical development. Psychiatry Res 2009;166:210-222.

101) Harfterkamp M, van de Loo-Neus G, Minderaa RB, van der Gaag RJ, Escobar R, Schacht A, et al. A randomized double-blind study of atomoxetine versus placebo for attention-deficit/hyperactivity disorder symptoms in children with autism spectrum disorder. J Am Acad Child Adolesc Psychiatry 2012;51:733-741.

102) Ming X, Gordon E, Kang N, Wagner GC. Use of clonidine in children with autism spectrum disorders. Brain Dev 2008;30:454-460.

103) Fankhauser MP, Karumanchi VC, German ML, Yates A, Karumanchi SD. A double-blind, placebo-controlled study of the efficacy of transdermal clonidine in autism. J Clin Psychiatry 1992;53: $77-82$.

104) Jaselskis CA, Cook EH Jr, Fletcher KE, Leventhal BL. Clonidine treatment of hyperactive and impulsive children with autistic disorder. J Clin Psychopharmacol 1992;12:322-327.

105) Becker K, Sinzig JK, Holtmann M. 'Attention deficits and subclinical epileptiform discharges: are EEG diagnostics in ADHD optional or essential?' Dev Med Child Neurol 2004;46:501-502.

106) Austin JK, Harezlak J, Dunn DW, Huster GA, Rose DF, Ambrosius WT. Behavior problems in children before first recognized seizures. Pediatrics 2001;107:115-122.

107) Salpekar JA, Dunn DW. Psychiatric and psychosocial consequences of pediatric epilepsy. Semin Pediatr Neurol 2007;14:181-188.

108) Caplan R. Psychopathology in pediatric epilepsy: role of antiepileptic drugs. Front Neurol 2012;3:163.

109) Gucuyener K, Erdemoglu AK, Senol S, Serdaroglu A, Soysal S, Kockar AI. Use of methylphenidate for attention-deficit hyperactivity disorder in patients with epilepsy or electroencephalographic abnormalities. J Child Neurol 2003:18:109-112.

110) Wernicke JF, Holdridge KC, Jin L, Edison T, Zhang S, Bangs ME, et al. Seizure risk in patients with attention-deficit-hyperactivity disorder treated with atomoxetine. Dev Med Child Neurol 2007;49: 498-502.

111) Dunn DW, Kronenberger WG. Childhood epilepsy, attention problems, and ADHD: review and practical considerations. Semin Pediatr Neurol 2005;12:222-228.

112) Surman CBH. ADHD in adults. A practical guide to evaluation and management. New York: Humana Press;2013.

113) Yang SJ, Cheong S, Hong SD. Prevalence and correlates of attention deficit hyperactivity disorder: school-based mental health services in Seoul. J Korean Neuropsychiatr Assoc 2006;45:69-76.

114) Hong M, Kwack YS, Joung YS, Lee SI, Kim B, Sohn SH, et al. Nationwide rate of attention-deficit hyperactivity disorder diagnosis and pharmacotherapy in Korea in 2008-2011. Asia Pac Psychiatry 2014;6:379-385.

115) Park TW. Treatment maintenance for ADHD. In: Ahn DH, Kim BS, Du JI, Park TW, Bahn GH, Shin MS, et al., editors. Integrative understanding of ADHD. Seoul: Hakjisa;2015. p.209-220.

116) Bhang SY, Kwack YS, Joung YS, Lee SI, Kim B, Sohn SH, et al. Factors that affect the adherence to ADHD medications during a treatment continuation period in children and adolescents: a nationwide retrospective cohort study using Korean health insurance date from 2007 to 2011. Psychiatry Investig 2017;14:158-165.

117) Young S, Murphy CM, Coghill D. Avoiding the 'twilight zone': recommendations for the transition of services from adolescence to adulthood for young people with ADHD. BMC Psychiatry 2011:11:174

118) Bhang SY, Hwang JW, Kwak YS, Joung YS, Lee S, Kim B, et al. Differences in utilization patterns among medications in children and adolescents with attention-deficit/hyperactivity disorder: a 36-month retrospective study using the Korean Health Insurance Review and Assessment Claims Database. J Korean Med Sci 2016;31:1284-1291.

119) American Psychiatric Association. Diagnostic and Statistical Manual of Mental Disorders. 4th ed. Washington, DC: American Psychiatric Association;1994.

120) American Psychiatric Association. Diagnostic and Statistical Manual of Mental Disorders (DSM-5®). 5th ed. Washington, DC: American Psychiatric Association;2013.

121) Treuer T, Chan KL, Kim BN, Kunjithapatham G, Wynchank D, Semerci B, et al. Lost in transition: a review of the unmet need of patients with attention deficit/hyperactivity disorder transitioning to adulthood. Asia Pac Psychiatry 2016 Aug 23 [Epub ahead of print]. http://dx.doi.org/10.1111/appy.12254.

122) Jaber L, Kirsh D, Diamond G, Shuper A. Long-term functional outcomes in Israeli adults diagnosed in childhood with attention deficit hyperactivity disorder. Isr Med Assoc J 2015;17:481-485.

123) London AS, Landes SD. Attention deficit hyperactivity disorder 
and adult mortality. Prev Med 2016;90:8-10.

124) Dalsgaard S, Østergaard SD, Leckman JF, Mortensen PB, Pedersen MG. Mortality in children, adolescents, and adults with attention deficit hyperactivity disorder: a nationwide cohort study. Lancet 2015;385:2190-2196.

125) Kooij JJ, Michielsen M, Kruithof H, Bijlenga D. ADHD in old age: a review of the literature and proposal for assessment and treatment. Expert Rev Neurother 2016;16:1371-1381.

126) Walker JS, Coleman D, Lee J, Squire PN, Friesen BJ. Children's stigmatization of childhood depression and ADHD: magnitude and demographic variation in a national sample. J Am Acad Child Adolesc Psychiatry 2008;47:912-920.

127) Lee S, Choi JW, Kim KM, Kim JW, Kim S, Kang T, et al. The guideline of diagnosis and treatment of attention-deficit hyperactivity disorder: developed by ADHD translational research center. J Korean Acad Child Adolesc Psychiatry 2016;27:236-266.

128) Hong M, Kim B, Hwang JW, Bhang SY, Choi HY, Oh IH, et al.
Naturalistic pharmacotherapy compliance among pediatric patients with attention deficit/hyperactivity disorder: a study based on three-year nationwide data. J Korean Med Sci 2016;31:611-616.

129) Wang LJ, Yang KC, Lee SY, Yang CJ, Huang TS, Lee TL, et al. Initiation and persistence of pharmacotherapy for youths with attention deficit hyperactivity disorder in Taiwan. PLoS One 2016;11: e0161061.

130) Hwangbo R, Chang H, Hong M, Cho S, Bahn GH. The diagnostic distribution of psychiatric disorders among the population under 19 years old: based on the national insurance data. J Korean Acad Child Adolesc Psychiatry 2016;27:139-145.

131) Soendergaard HM, Thomsen PH, Pedersen P, Pedersen E, Poulsen AE, Nielsen JM, et al. Treatment dropout and missed appointments among adults with attention-deficit/hyperactivity disorder: associations with patient- and disorder-related factors. J Clin Psychiatry 2016;77:232-239. 